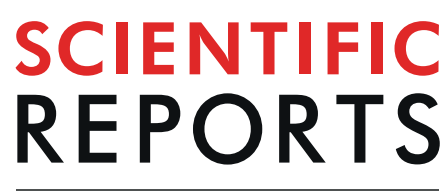

natureresearch

\title{
OPEN Particulate matter-attributable mortality and relationships with carbon dioxide in 250 urban areas worldwide
}

Received: 25 April 2019

Published online: 09 August 2019

\author{
Susan C. Anenberg $\mathbb{1}^{1}$, Pattanun Achakulwisut ${ }^{1,7}$, Michael Braver $\mathbb{1}^{2,3}$, Daniel Moran ${ }^{4}$, \\ Joshua S. Apte ${ }^{5}$ \& Daven K. Henze $\mathbb{B}^{6}$
}

Urban air pollution is high on global health and sustainability agendas, but information is limited on associated city-level disease burdens. We estimated fine particulate matter $\left(P_{2.5}\right)$ mortality in the 250 most populous cities worldwide using $\mathrm{PM}_{2.5}$ concentrations, population, disease rates, and concentration-response relationships from the Global Burden of Disease 2016 Study. Only $8 \%$ of these cities had population-weighted mean concentrations below the World Health Organization guideline for annual average $\mathrm{PM}_{2.5}$. City-level $\mathrm{PM}_{2.5}$-attributable mortality rates ranged from 13-125 deaths per 100,000 people. $\mathrm{PM}_{2.5}$ mortality rates and carbon dioxide $\left(\mathrm{CO}_{2}\right)$ emission rates were weakly positively correlated, with regional influences apparent from clustering of cities within each region. Across 82 cities globally, $\mathrm{PM}_{2.5}$ concentrations and mortality rates were negatively associated with city gross domestic product (GDP) per capita, but we found no relationship between GDP per capita and $\mathrm{CO}_{2}$ emissions rates. While results provide only a cross-sectional snapshot of cities worldwide, they point to opportunities for cities to realize climate, air quality, and health co-benefits through low-carbon development. Future work should examine drivers of the relationships (e.g. development stage, fuel mix for electricity generation and transportation, sector-specific $\mathrm{PM}_{2.5}$ and $\mathrm{CO}_{2}$ emissions) uncovered here and explore uncertainties to test the robustness of our conclusions.

Urban air pollution is high on the global sustainable development agenda ${ }^{1-3}$. The world's urban population is expected to grow from $>50 \%$ of today's global population to $66 \%$ by $2050^{4}$, with urban areas projected to absorb all population growth. Efforts to address urban air pollution by intergovernmental organizations, global networks (e.g. C40 cities, Global Urban Air Pollution Observatory), national governments, and individual cities can benefit from quantitative estimates of urban air pollution-related health impacts. Such estimates can help prioritize mitigation actions in cities (e.g. investing in electric buses, public transportation, and active urban mobility) and can motivate national scale policies (e.g. ambient air quality standards, emission standards for sources such as vehicles). Furthermore, since combustion is a major source of greenhouse gases and air pollution ${ }^{5}$, cities can reap immediate and local health benefits while also contributing to reductions of combustion-related climate-forcing pollutants ${ }^{6}$. Air pollution disease burdens by source sector have been quantified at the national level ${ }^{7,8}$ and city level for individual cities ${ }^{9-11}$ but information is limited for cities globally.

Ambient $\mathrm{PM}_{2.5}$ is considered the leading environmental health risk factor globally and is a top 10 risk factor in countries across the economic development spectrum ${ }^{12}$. Early studies estimating the global burden of disease from air pollution focused on cities, where most of the world's ground-based monitors were located ${ }^{13}$. Currently the most comprehensive global burden of disease studies report estimates at the national scale (sub-national for some countries) $)^{12,14}$, enabled by the full global coverage and high resolution of satellite remote sensing of aerosol

${ }^{1}$ Milken Institute School of Public Health, George Washington University, Washington DC, USA. ${ }^{2}$ School of Population and Public Health, University of British Columbia, Vancouver, British Columbia, Canada. ${ }^{3}$ Institute for Health Metrics and Evaluation, University of Washington, Seattle, Washington, USA. ${ }^{4}$ Norwegian University of Science and Technology, Trondheim, Norway. ${ }^{5}$ Department of Civil, Architectural and Environmental Engineering, University of Texas - Austin, Austin, Texas, USA. ${ }^{6}$ University of Colorado - Boulder, Boulder, Colorado, USA. ${ }^{7}$ Stockholm Environment Institute, Seattle, Washington, USA. Correspondence and requests for materials should be addressed to S.C.A. (email: sanenberg@gwu.edu) 


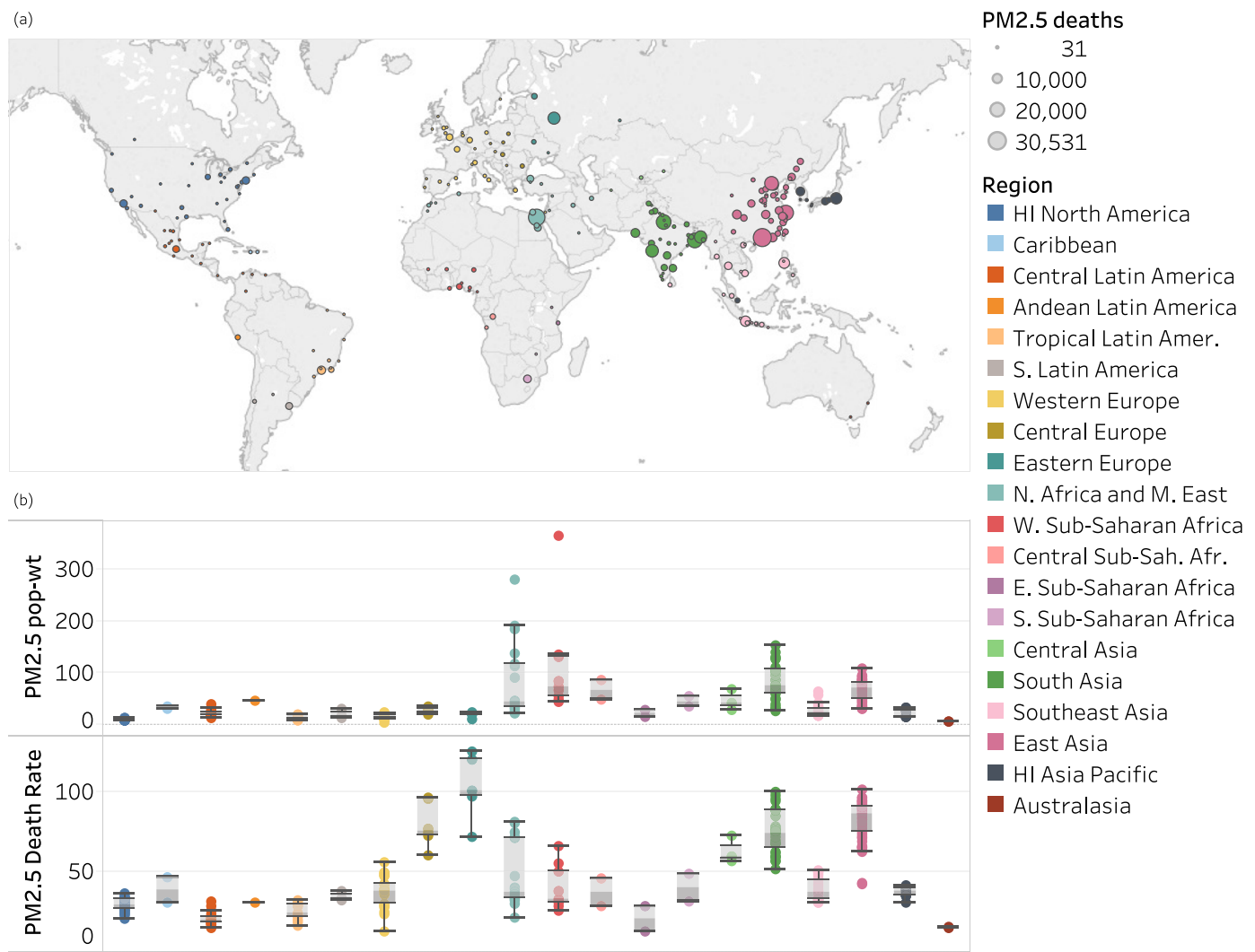

Figure 1. $\mathrm{PM}_{2.5}$-attributable premature deaths in 2016 in 250 cities worldwide. (a) Number of $\mathrm{PM}_{2.5^{-}}$ attributable deaths on a world map; (b) Box plots of population-weighted annual average $\mathrm{PM}_{2.5}$ concentration (PM2.5 pop-wt) and $\mathrm{PM}_{2.5}$ attributable deaths per 100,000 people (PM2.5 death rate) across all cities in each region. Boxes indicate the middle $50 \%$ of the data; whiskers show data within 1.5 times the interquartile range. $\mathrm{HI}=$ High-Income.

optical depth ${ }^{15}$. Here, we exploit these global, highly resolved $\mathrm{PM}_{2.5}$ concentrations to estimate the burden of disease attributable to $\mathrm{PM}_{2.5}$ in 250 major cities worldwide. Unlike previous estimates of air pollution disease burdens among subsets of cities ${ }^{16-18}$, our globally consistent methods enable comparisons across cities worldwide and are compatible with the Global Burden of Disease 2016 (GBD 2016) Study ${ }^{12}$.

\section{Results}

We first estimated $\mathrm{PM}_{2.5}$-attributable mortality in 2016 for the 250 most populous urban areas (see Methods regarding the city definition). The median population-weighted $\mathrm{PM}_{2.5}$ concentration was $29 \mu \mathrm{g} / \mathrm{m}^{3}$ [standard deviation $(\mathrm{sd})=43 \mu \mathrm{g} / \mathrm{m}^{3}$, range $5-365 \mu \mathrm{g} / \mathrm{m}^{3}$; Fig. 1], three times greater than the WHO guideline for annual average $\mathrm{PM}_{2.5}\left(10 \mu \mathrm{g} / \mathrm{m}^{3}\right)$. Among the 250 cities, only $21(8 \%$, all in Sweden, the US, Canada, Australia, and Brazil) had population-weighted mean concentrations below the guideline, whereas 104 (42\%) exceeded the WHO Interim Target $1\left(35 \mu \mathrm{g} / \mathrm{m}^{3}\right)$. The median rate of $\mathrm{PM}_{2.5}$-attributable deaths was 39 deaths per 100,000 people (sd $=26$, range 13-125 per 100,000 people; Fig. 1). Several regions show large variability in city-specific rate of $\mathrm{PM}_{2.5}$-attributable deaths (Fig. 1). While the top 10 cities for population-weighted $\mathrm{PM}_{2.5}$ were mostly in Africa and Asia, the top 10 for $\mathrm{PM}_{2.5}$-attributable mortality rate were all in Asia and Europe (Fig. S1 and Table S1), driven by high cardiopulmonary disease rates in Europe and high $\mathrm{PM}_{2.5}$ concentrations in Asia. High concentrations in Northern Africa and Middle East cities are partly driven by wind-blown mineral dust, which is mostly naturally-occurring. Cities in Australia, Brazil, Canada, Sweden, and the U.S. that had $\mathrm{PM}_{2.5}$ concentrations below the WHO guideline were in the lowest quartile of $\mathrm{PM}_{2.5}$-attributable mortality rates among these 250 cities.

To explore whether cities with high particulate air pollution are also large $\mathrm{CO}_{2}$ emitters, we compared city-level $\mathrm{PM}_{2.5}$ concentrations and mortality rates to local $\mathrm{CO}_{2}$ emissions. We found no association between $\mathrm{PM}_{2.5}$ concentrations and $\mathrm{CO}_{2}$ emission rates (Fig. 2a). $\mathrm{PM}_{2.5}$ mortality rates and $\mathrm{CO}_{2}$ emission rates were weakly positively correlated, though with regional influences on $\mathrm{PM}_{2.5}$ mortality rates apparent from clustering of cities in the same region (Fig. $2 \mathrm{~b}$ and Fig. S2). This clustering may result from national-scale policies, regional pollution transport, and other factors (e.g. geographical or meteorological) affecting many cities simultaneously. The national disease rates used in this study also contribute to regional clustering in the $\mathrm{PM}_{2.5}$ death rates. Many Asian cities are among the highest for $\mathrm{PM}_{2.5}$ mortality rate but only 10 Asian cities emit more $\mathrm{CO}_{2}$ per 100,000 people than the largest high-income emitters. Contrastingly, high-income North American 
(a)

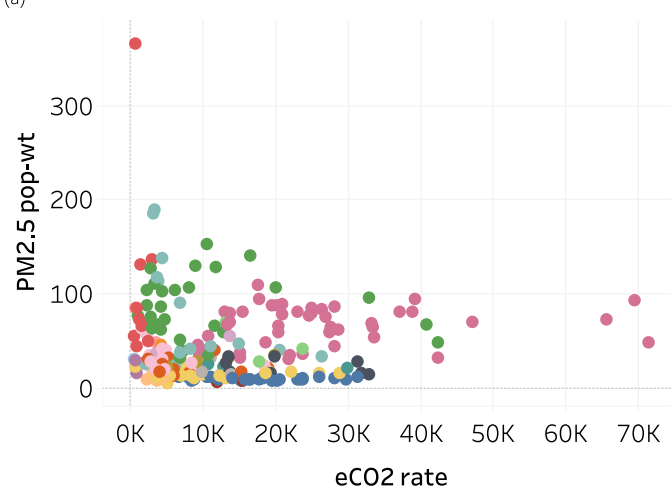

(b)

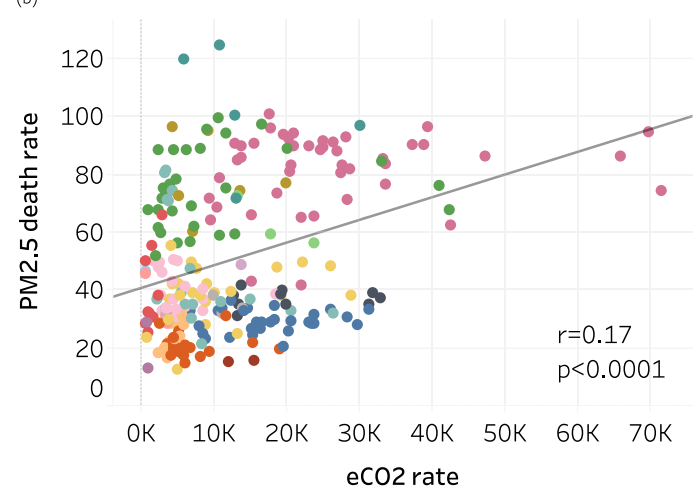

(c)

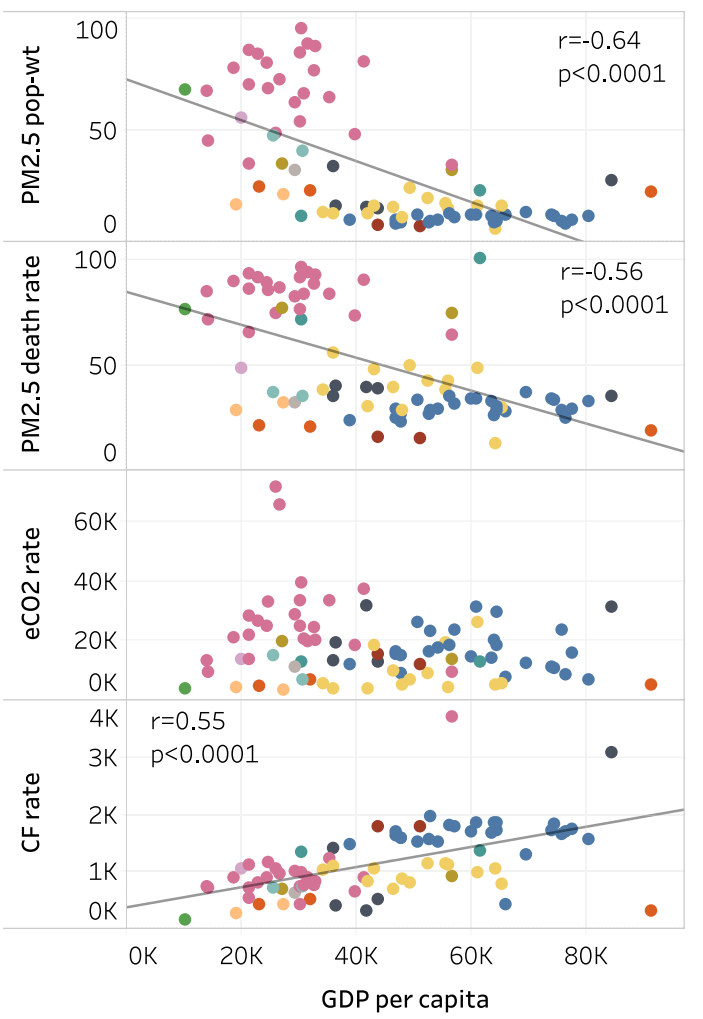

Figure 2. City-specific estimates of $\mathrm{PM}_{2.5}$-attributable premature deaths per capita in 2016 versus other city indicators. (a) Population-weighted annual average $\mathrm{PM}_{2.5}$ concentration $\left(\mu \mathrm{g} / \mathrm{m}^{3}\right)$ vs. annual $\mathrm{CO}_{2}$ emissions rate (t C per 100,000 people); (b) $\mathrm{PM}_{2.5}$ death rate (deaths per 100,000 people) vs. annual $\mathrm{CO}_{2}$ emissions rate; (c) comparison of population-weighted $\mathrm{PM}_{2.5}, \mathrm{PM}_{2.5}$ death rate, $\mathrm{CO}_{2}$ emissions rate, and 2013 carbon footprint rate (kt $\mathrm{CO}_{2}$ per 100,000 people) vs. GDP per capita (\$) in 2015 in 82 cities. Colors indicate world regions (see Fig. 1 legend). Linear regression lines are shown where correlations are significant, $r$ is the correlation coefficient, and $\mathrm{p}$ is the correlation significance level. (Note: Riyadh was removed from panels a and $\mathrm{b}$ to show more detail in the rest of the dataset. Its $\mathrm{CO}_{2}$ emission rate is likely unrealistically high due to very low population estimate in the GPWv4 dataset: $\mathrm{CO}_{2}$ emission rate $=290,000 \mathrm{kt} \mathrm{CO}$ per 100,000 people, $\mathrm{PM}_{2.5}$ pop-wt $=280 \mu \mathrm{g} / \mathrm{m}^{3}$, and $\mathrm{PM}_{2.5}$ death rate $=40$.) Similar graphs for each region (using "super-regions" from the Global Burden of Disease 2016 Study) and the 50 most populous cities globally are in the Supplemental Information (Figs S5-S12).

cities have low $\mathrm{PM}_{2.5}$ mortality rates but mid- to-high $\mathrm{CO}_{2}$ emissions rates. European and African cities range from low to very high for $\mathrm{PM}_{2.5}$ mortality rates but African cities are relatively low and European cities in the mid-range for $\mathrm{CO}_{2}$ emissions rates. To explore the influence of economic development, we compared population-weighted $\mathrm{PM}_{2.5}$ concentration, $\mathrm{PM}_{2.5}$-attributable mortality rates, and $\mathrm{CO}_{2}$ emissions to city-level gross domestic product (GDP; Fig. 2c). Across 82 cities with available city-specific GDP data, $\mathrm{PM}_{2.5}$ concentrations and mortality rates were negatively associated with city GDP per capita, but no relationship exists between GDP per capita and $\mathrm{CO}_{2}$ emissions rates.

To further elucidate why $\mathrm{PM}_{2.5}$ concentrations and mortality decline more than $\mathrm{CO}_{2}$ emissions with increasing GDP, we compared $\mathrm{PM}_{2.5}$ deaths against consumption-based carbon footprints, which account for $\mathrm{CO}_{2}$ emitted worldwide from production of locally-consumed goods. North American and European cities, which are high consumers of products manufactured elsewhere, are ranked higher among the 250 cities for carbon footprints compared with local $\mathrm{CO}_{2}$ emissions (Fig. S3). The opposite is true for most Asian cities, where export-dominated manufacturing prevails. The positive relationship between GDP per capita and carbon footprint is expected since GDP was an input to estimate urban carbon footprints ${ }^{19}$. The pattern of large carbon footprints but low $\mathrm{PM}_{2.5}$ mortality rates in North American cities, and small carbon footprints but high $\mathrm{PM}_{2.5}$ mortality rates in Asian cities potentially indicates that many cities with large carbon footprints (e.g. U.S. cities) have exported $\mathrm{PM}_{2.5}$ and health impacts to other places (e.g. Asian cities) which manufacture consumption goods that are then imported elsewhere, as explored previously e.g. ${ }^{20}$. To identify cities that are performing better or worse than predicted by the linear per capita GDP-PM ${ }_{2.5}$ deaths relationship, we examined the regression residuals. Mexico City, Monterrey, Rio de Janeiro, Sao Paolo and Melbourne had lower $\mathrm{PM}_{2.5}$ mortality rates compared with their predicted values, while Wuxi, Tianjin, Wuhan, Moscow and Warsaw had higher mortality rates than expected based upon GDP per capita. 


\section{Discussion}

These analyses provide the first estimates of the $\mathrm{PM}_{2.5}$ disease burden in urban areas worldwide using methods that are globally consistent (enabling comparisons across cities globally) and compatible with the Global Burden of Disease 2016 Study. Estimated $\mathrm{PM}_{2.5}$-attributable deaths per 100,000 people varied by a factor of 10 across the 250 most populous cities worldwide, indicating that some cities are achieving far lower levels of air pollution-related health impacts than others. We found a weakly positive correlation between $\mathrm{PM}_{2.5}$ mortality and $\mathrm{CO}_{2}$ emission rates, which suggests that there may be opportunities for cities to achieve climate and air quality co-benefits through mitigation measures that address both $\mathrm{PM}_{2.5}$ and $\mathrm{CO}_{2}$. In contrast, we found that while regions with wealthier cities have reduced their $\mathrm{PM}_{2.5}$ concentrations and mortality burdens considerably, $\mathrm{CO}_{2}$ emissions have not declined in parallel. This first cross-sectional snapshot of cities globally does not allow for drawing strong conclusions as to the factors driving these relationships. However, we suspect that several explanations for these relationships may be occurring in concert: (1) historical tendency in developed countries to address air quality by implementing end-of-pipe emission controls that reduce air pollution but not carbon (e.g. diesel particulate filters on vehicles, scrubbers that remove sulfur dioxide emissions from power plants); (2) movement of industry and power generation out of cities, while the relatively "clean" energy sources remaining in cities still produce $\mathrm{CO}_{2}$ emissions; (3) "out-sourcing" manufacturing and associated pollution from wealthy cities to other locations around the world, where lax environmental regulations may result in more emissions per unit energy consumed. While the first factor reduces $\mathrm{PM}_{2.5}$ levels, the second two simply move pollution from one place to another without necessarily improving air quality overall. Future research could examine these and other characteristics of cities, such as development stage, fuel mix for electricity generation and transportation, and sector-specific emissions of $\mathrm{PM}_{2.5}$ and $\mathrm{CO}_{2}$, in more detail and over time, to further elucidate the drivers of the relationships uncovered here.

The world faces a challenge as urbanization rapidly expands populations mainly in Asian and African cities, where $\mathrm{PM}_{2.5}$ levels are also mostly trending upward ${ }^{21}$. This initial analysis of city air pollution burdens using globally consistent methods paints a salient yet still emerging lesson: to slow climate change, improve air quality, and protect public health simultaneously, historically "successful" air quality management programs may not be enough. Low carbon development, however, can avoid the fossil fuel combustion that releases both air pollution and greenhouse gases. As air pollution remains a top 10 risk factor for most countries globally, all cities, even those with relatively low $\mathrm{PM}_{2.5}$ mortality rates, can improve local public health by transitioning away from fossil fuels. Thus, the challenge of urban $\mathrm{PM}_{2.5}$ can also be viewed as an opportunity - reducing fossil fuel combustion offers local and immediate air quality and public health benefits, in addition to slowing climate change globally and over centuries. This opportunity can be realized in many ways, including by improving building energy efficiency, displacing vehicular traffic with active transportation, electrifying public transportation, and transitioning to renewables for power generation. Several of these approaches would have additional co-benefits from fewer road traffic collisions, more physical activity, less noise pollution, and other improvements.

Several limitations may affect the strength of our conclusions. While our top-down, globally consistent approach offers consistency and broad coverage (providing $\mathrm{PM}_{2.5}$ mortality estimates for many cities which otherwise would have none), bottom-up and local data could improve estimates for individual cities. For example, though we used national disease rates, subnational disease rates can vary by $\pm 20-40 \%$ or more compared to national average rates ${ }^{22}$. This additional heterogeneity is not captured here, but is small relative to the global differences we estimate. We neglected uncertainty in the input variables, though $\mathrm{PM}_{2.5}$ concentrations, relative risks, $\mathrm{CO}_{2}$ emissions, carbon footprints, and city GDP are each uncertain and may vary between existing datasets and inventories ${ }^{23} . \mathrm{PM}_{2.5}$ concentrations are uncertain because much of the world still lacks ground monitoring networks, though most monitors included by Shaddick et al. ${ }^{15}$ were in cities. Beyond $\mathrm{PM}_{2.5}$, urban populations are also exposed to ground-level ozone, nitrogen dioxide, and other combustion-related air pollutants. $\mathrm{PM}_{2.5}$ is also associated with other health outcomes, including asthma ${ }^{24}$, excluded here for consistency with the 2016 GBD. Our analysis is cross-sectional and could be supplemented with future longitudinal analysis to identify determinants of $\mathrm{PM}_{2.5}-\mathrm{CO}_{2}$ relationships (e.g. city size, population, and geographical location) and consider other climate warming pollutants. Exploring uncertainties and their influences on city-level $\mathrm{PM}_{2.5}$-attributable mortality estimates could also test the robustness of these results and conclusions.

\section{Methods}

We estimated $\mathrm{PM}_{2.5}$ health impacts using $\mathrm{PM}_{2.5}$ concentration $\left(0.1^{\circ} \times 0.1^{\circ} \text { grid resolution }\right)^{15}$, population, national baseline disease rates, and concentration-response relationships from the GBD 2016 ${ }^{12,25}$. Annual average $\mathrm{PM}_{2.5}$ concentrations were estimated by combining satellite-derived aerosol optical depth with vertical aerosol distribution from a chemical transport model, calibrated to 6,003 measurements from 117 countries. Gridcell concentrations ranged from 0.9 to $990 \mu \mathrm{g} / \mathrm{m}^{3}$ globally. Gridded population counts aggregated to $0.1^{\circ} \times 0.1^{\circ}$ are from the CIESIN Gridded Population of the World v4 (total in 2016 was 7.28 billion; http://sedac.ciesin.columbia.edu/ data/collection/gpw-v4, accessed August 17, 2018). We downloaded country-, age-, and cause- specific baseline deaths in 2016 from the GBD Data Exchange (http://ghdx.healthdata.org/gbd-results-tool, accessed June 1, 2018).

We calculated age- and cause-specific relative risk of disease for each gridcell $\mathrm{PM}_{2.5}$ concentration using Integrated Exposure Response (IER) curves ${ }^{25}$. The shape of the IERs depends on the health endpoint, and flattens at very high concentrations, particularly for cardiovascular endpoints. We created lookup tables in $0.1 \mu \mathrm{g} /$ $\mathrm{m}^{3}$ increments of $\mathrm{PM}_{2.5}$ concentration, following previous studies ${ }^{26,27}$. Central estimates of $\mathrm{PM}_{2.5}$-attributable health impacts were calculated using the mean of the 1000 IER parameter draws for each health endpoint, and $95 \%$ confidence intervals were calculated using the $2.5^{\text {th }}$ and $97.5^{\text {th }}$ percentiles. We applied theoretical minimum risk exposure levels included with the IER parameter dataset from a uniform distribution of 2.4 to $5.9 \mu \mathrm{g} / \mathrm{m}^{3}$. All calculations were performed in MATLAB r2013b and R v3.4.2. 
Globally, we estimate that ambient annual average $\mathrm{PM}_{2.5}$ in 2016 was associated with 4.1 million deaths (95\% confidence interval, 2.3-6.1 million), within $0.3 \%$ of GBD 2016 results $^{25}$. Approximately $20 \%, 39 \%, 19 \%, 7 \%$, and $16 \%$ were from stroke, ischemic heart disease, chronic obstructive pulmonary disease, lung cancer, and lower respiratory infections, respectively.

For city-specific $\mathrm{PM}_{2.5}$ mortality, we summed gridded $\mathrm{PM}_{2.5}$ mortality estimates within urban spatial extents from the Global Human Settlement grid (GHS-SMOD) for 2015 at $1 \mathrm{~km}$ resolution (https://ghsl.jrc.ec.europa. eu/ghs_smod.php, Accessed August 17, 2018) ${ }^{28}$. We defined cities following the "urban centers or high density clusters" definition, with $\geq 1,500$ inhabitants per $\mathrm{km}^{2}$ or a density of built-up $\geq 50 \%$ and $\geq 50,000$ inhabitants. We matched GHS-SMOD city identifiers to city names in ArcGIS. GHS-SMOD city definitions treat patches of dense contiguous urban fabric (e.g. Tokyo-Kawasaki-Kawagoe-Hachioji-Yokohama) as one large "city". Scaling the $1 \mathrm{~km}$ urban definition grid to the $0.1^{\circ} \times 0.1^{\circ}$ resolution of our disease burden estimates resulted in loss of urban spatial extent, population, and air pollution-attributable deaths compared with the finer resolution. Therefore, to retain as much data as possible, we multiplied our estimated air pollution-attributable deaths in each urban area at $0.1^{\circ} \times 0.1^{\circ}$ by the ratio of population in each urban area calculated at high-resolution $\left(0.0083^{\circ} \times 0.0083^{\circ}\right.$, or $\sim 1 \mathrm{~km})$ versus low resolution $\left(0.1^{\circ} \times 0.1^{\circ}\right)$.

City fossil fuel $\mathrm{CO}_{2}$ emissions in 2016 are from the Open-source Data Inventory for Anthropogenic $\mathrm{CO}_{2}$ (ODIAC), a globally gridded $(1 \mathrm{~km})$ satellite-derived dataset ${ }^{29}$. City carbon footprints (for 2013$)$ are from recently published estimates for 13,000 cities using the same GHS-SMOD city definitions (http://citycarbonfootprints. info/, Accessed August 17, 2018) ${ }^{19}$. Briefly, national carbon footprints were spatially allocated based on population, purchasing power, and existing subnational estimates from the U.S., China, the European Union, and Japan. $\mathrm{CO}_{2}$ emissions are production-based, while carbon footprints are consumption-based. GDP estimates for 2015 are from a Brookings Institution report ${ }^{30}$. Statistical associations are indicated for a significance level of $\mathrm{p}<0.05$.

Population-normalized rates were calculated using the GBD population dataset used to calculate $\mathrm{PM}_{2.5}$ mortality, except carbon footprints which were estimated with GHS-POP population. Fig. S4 compares the two population datasets.

\section{Data Availability}

Results for all 250 urban areas, including cities within each urban cluster, country, region, $\mathrm{PM}_{2.5}$ concentrations, and $\mathrm{PM}_{2.5}$ mortality are available at: https://figshare.com/articles/_/7871747. All other data used in this study are either publicly available or are available from the authors upon request.

\section{References}

1. United Nations General Assembly. Resolution adopted by the General Assembly on 25 September 2015: 70/1. Transforming our world: the 2030 Agenda for Sustainable Development (2015). Available at: https://www.un.org/en/development/desa/population/ migration/generalassembly/docs/globalcompact/A_RES_70_1_E.pdf (accessed August 1, 2019).

2. World Health Organization. Health and the Environment: Addressing the health impact of air pollution (2015). Available at: https:// apps.who.int/iris/handle/10665/253206 (accessed August 1, 2019).

3. United Nations. New Urban Agenda. (2016). Available at: http://habitat3.org/the-new-urban-agenda/ (accessed August 1, 2019).

4. United Nations. World Urbanization Prospects: The 2014 Revision (2014). Available at: https://population.un.org/wup/Publications/ Files/WUP2014-Report.pdf (accessed August 1, 2019).

5. Lelieveld, J., Evans, J. S., Fnais, M., Giannadaki, D. \& Pozzer, A. The contribution of outdoor air pollution sources to premature mortality on a global scale. Nature 525, 367-371 (2015).

6. West, J. J. et al. Co-benefits of mitigating global greenhouse gas emissions for future air quality and human health. Nature Clim. Change 3, 885-889 (2013).

7. GBD MAPS Working Group. Special Report 20: Burden of Disease Attributable to Coal-Burning and Other Major Sources of Air Pollution in China. (2016). Available at: https://www.healtheffects.org/system/files/GBDMAPS-ExecSummEnglishFinal.pdf (accessed August 1, 2019).

8. Health Effects Institute. Special Report 21: Burden of Disease Attributable to Major Air Pollution Sources in India (2018). Available at: https://www.healtheffects.org/system/files/GBD-MAPS-SpecRep21-India-revised_0.pdf (accessed August 1, 2019).

9. Kheirbek, I., Haney, J., Douglas, S., Ito, K. \& Matte, T. The contribution of motor vehicle emissions to ambient fine particulate matter public health impacts in New York City: a health burden assessment. Environmental Health 15, 89 (2016).

10. Karagulian, F. et al. Contributions to cities' ambient particulate matter (PM): A systematic review of local source contributions at global level. Atmospheric Environment 120, 475-483 (2015).

11. Bhanarkar, A. D. et al. Managing future air quality in megacities: Co-benefit assessment for Delhi. Atmospheric Environment 186, 158-177 (2018).

12. GBD 2016 Risk Factors Collaborators. Global, regional, and national comparative risk assessment of 84 behavioral, environmental and occupational, and metabolic risks or clusters of risks, 1990-2016: a systematic analysis for the Global Burden of Disease Study 2016. The Lancet 390, 1345-1422 (2017).

13. Cohen, A. et al. Urban Air Pollution. In Comparative Quantification of Health Risks: Global and Regional Burden of Disease Due to Selected Major Risk Factors 1353-434 (World Health Organization, 2004).

14. World Health Organization. Preventing disease through healthy environments: a global assessment of the burden of disease from environmental risks. (2016). Available at: http://apps.who.int/iris/bitstream/10665/204585/1/9789241565196_eng.pdf?ua=1 (accessed August 1, 2019).

15. Shaddick, G. et al. Data integration for the assessment of population exposure to ambient air pollution for Global Burden of Disease Assessment. Environmental Science \& Technology, https://doi.org/10.1021/acs.est.8b02864 (2018).

16. Maji, K. J., Arora, M. \& Dikshit, A. K. Burden of disease attributed to ambient PM2.5 and PM10 exposure in 190 cities in China. Environmental Science and Pollution Research 24, 11559-11572 (2017).

17. Lin, H. et al. Mortality burden of ambient fine particulate air pollution in six Chinese cities: Results from the Pearl River Delta study. Environment International 96, 91-97 (2016).

18. Marlier, M. E., Jina, A. S., Kinney, P. L. \& DeFries, R. S. Extreme air pollution in global megacities. Current Climate Change Reports 2, 15-27 (2016)

19. Moran, D. et al. Carbon footprints of 13000 cities. Environmental Research Letters 13, 064041 (2018).

20. Moran, D. \& Kanemoto, K. Tracing global supply chains to air pollution hotspots. Environmental Research Letters 11, 094017 (2016).

21. World Health Organization. Global Urban Air Pollution Database (update 2016). (2016). Available at: https://www.who.int/ airpollution/data/cities/en/ (accessed August 1, 2019). 
22. GBD 2017 Disease And Injury Incidence and Prevalence Collaborators. Global, regional, and national incidence, prevalence, and years lived with disability for 354 diseases and injuries for 195 countries and territories, 1990-2017: a systematic analysis for the Global Burden of Disease Study 2017. The Lancet 392, (2018).

23. Ru, M., Shindell, D. T., Seltzer, K. M., Tao, S. \& Zhong, Q. The long-term relationship between emissions and economic growth for $\mathrm{SO}_{2}, \mathrm{CO}_{2}$, and BC. Environmental Research Letters 13, 124021 (2018).

24. Anenberg, S. C. et al. Estimates of the global burden of ambient PM2.5, ozone, and $\mathrm{NO}_{2}$ on asthma incidence and emergency room visits. Environmental Health Perspectives 126, 107004 (2018).

25. Cohen, A. J. et al. Estimates and 25-year trends of the global burden of disease attributable to ambient air pollution: an analysis of data from the Global Burden of Diseases Study 2015. The Lancet, https://doi.org/10.1016/S0140-6736(17)30505-6 (2017).

26. Anenberg, S. et al. Impacts and mitigation of excess diesel-related NOx emissions in 11 major vehicle markets. Nature 545, 467-471 (2017).

27. Apte, J. S., Marshall, J. D., Cohen, A. J. \& Brauer, M. Addressing global mortality from ambient PM2.5. Environ. Sci. Technol. 49, 8057-8066 (2015).

28. Pesaresi, M. \& Freire, S. GHS Settlement grid following the REGIO model 2014 in application to GHSL Landsat and CIESIN GPW v4-multitemporal (1975-1990-2000-2015). (European Commission, Joint Research Centre, 2016).

29. Oda, T. \& Maksyutov, S. A very high-resolution $(1 \mathrm{~km} \times 1 \mathrm{~km})$ global fossil fuel $\mathrm{CO}_{2}$ emission inventory derived using a point source database and satellite observations of nighttime lights. Atmospheric Chemistry and Physics 11, 543-556 (2011).

30. Trujillo, J. L. \& Parilla, J. Redefining Global Cities: The Seven Types of Global Metro Economies. (2016). The Brookings Institution. Available at: https://www.brookings.edu/wp-content/uploads/2016/09/metro_20160928_gcitypes.pdf (accessed August 1, 2019).

\section{Acknowledgements}

We are grateful to Casey Kalman for assistance with the urban definitions. We thank the many researchers who have contributed to the datasets used in our analysis. We appreciate the efforts by the Institute for Health Metrics and Evaluation and developers of the CIESIN, Global Human Settlement, and Open-source Data Inventory for Anthropogenic $\mathrm{CO}_{2}$ datasets to make their data and results publicly available. Funding was provided by George Washington University and the NASA Health and Air Quality Applied Science Team Award No. NNX16AQ26G.

\section{Author Contributions}

S.C.A. conceived of the project, S.C.A. and P.A. expanded the project idea and designed and performed the analysis, M.B. and D.M. provided data, S.C.A. drafted the paper, and all authors interpreted results and reviewed the paper.

\section{Additional Information}

Supplementary information accompanies this paper at https://doi.org/10.1038/s41598-019-48057-9.

Competing Interests: The authors declare no competing interests.

Publisher's note: Springer Nature remains neutral with regard to jurisdictional claims in published maps and institutional affiliations.

(c) (i) Open Access This article is licensed under a Creative Commons Attribution 4.0 International License, which permits use, sharing, adaptation, distribution and reproduction in any medium or format, as long as you give appropriate credit to the original author(s) and the source, provide a link to the Creative Commons license, and indicate if changes were made. The images or other third party material in this article are included in the article's Creative Commons license, unless indicated otherwise in a credit line to the material. If material is not included in the article's Creative Commons license and your intended use is not permitted by statutory regulation or exceeds the permitted use, you will need to obtain permission directly from the copyright holder. To view a copy of this license, visit http://creativecommons.org/licenses/by/4.0/.

(C) The Author(s) 2019 